\title{
GUANYIN IN BLANC DE CHINE
}

De uitgebreide porseleincollectie van het Rijksmuseum bevat een kleine groep beelden van blanc de Chine-porselein (afb. 1). Blanc de Chine is een bepaald type witbakkende porselein dat wordt vervaardigd in Dehua en omgeving, de hoofdstad van het gelijknamige district in de provincie Fujian. Vooral beelden van blanc de Chine waren in het Westen als exotisch souvenir vanaf het begin van de handelscontacten tussen China en het westen geliefd. De productie werd voor een deel ook speciaal op de westerse kopers afgestemd. Later - aan het begin van de twintigste eeuw - ontstond onder westerse verzamelaars ook oog voor de bijzondere kwaliteit van sommige van de beelden die juist niet voor de export, maar voor Chinezen werden gemaakt en een devotionele functie hadden.

\section{Datering van blanc de chine}

Het is niet eenvoudig om uitspraken te doen over de kwaliteit en datering van een stuk blanc de Chine. Dè autoriteit was tot voor kort (en is dat voor een deel nog steeds) P.J. Donnelly die met zijn boek Blanc de Chine in 1969 een schat aan informatie en afbeeldingen bundelde en beschikbaar stelde. Het hoogtepunt van de productie van blanc de Chine-beelden plaatste hij in de Kangxi-periode (1662-1722). Het werk van He Chaozong, van naam bekend vanwege zijn merk dat voorkomt op een aantal zeer fraaie beelden, neemt - volgens Donnelly - in deze productie uit de Kangxi-periode een centrale plaats in. Deze visie is in de afgelopen jaren bijgesteld. In 2002 verschenen drie boeken over blanc de Chine-porselein. ${ }^{1}$ Twee daarvan zijn gezamenlijk door Chinese en westerse auteurs geschreven en ook het derde boek maakt zoveel mogelijk gebruik van Chinese publicaties. Eén van de nieuwe inzichten is dat de bloeiperiode èn het werk van He Chaozong vroeger moet worden gedateerd, en wel in de eerste helft van de $17^{e}$ eeuw. Twee beelden met He Chaozongs merk èn met een datering (1618 en 1619) zijn intussen bekend en zij vormen een belangrijk uitgangspunt voor de datering van andere stukken. ${ }^{2}$ Het werk van He en verwante modelleurs stamt dus niet uit de Qing-dynastie (1644-1911), maar uit de late Ming-tijd (1368-1644), een 'gouden' eeuw voor de provincie Fujian, waar het mecenaat van een rijke en ontwikkelde koopmansklasse voor een bloei van de kunsten zorgde. De invloed van Peking was gering en boeddhistische sectes met speciale wensen voor beelden in hun tempels floreerden. De modelleurs moeten gezocht worden in de kringen van kunst-handwerkslieden die beelden sneden in hout en steen. Het model waarvan een mal werd gemaakt en waarmee vervolgens een serie beelden in porselein kon worden gemaakt, werd waarschijnlijk in hout gesneden. Dat He Chaozong bekend is geworden komt niet alleen door zijn merk, zijn naam wordt ook genoemd in een

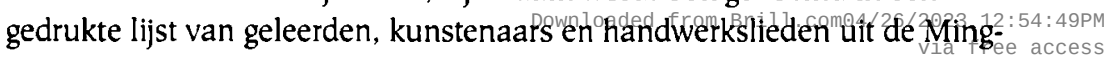


28

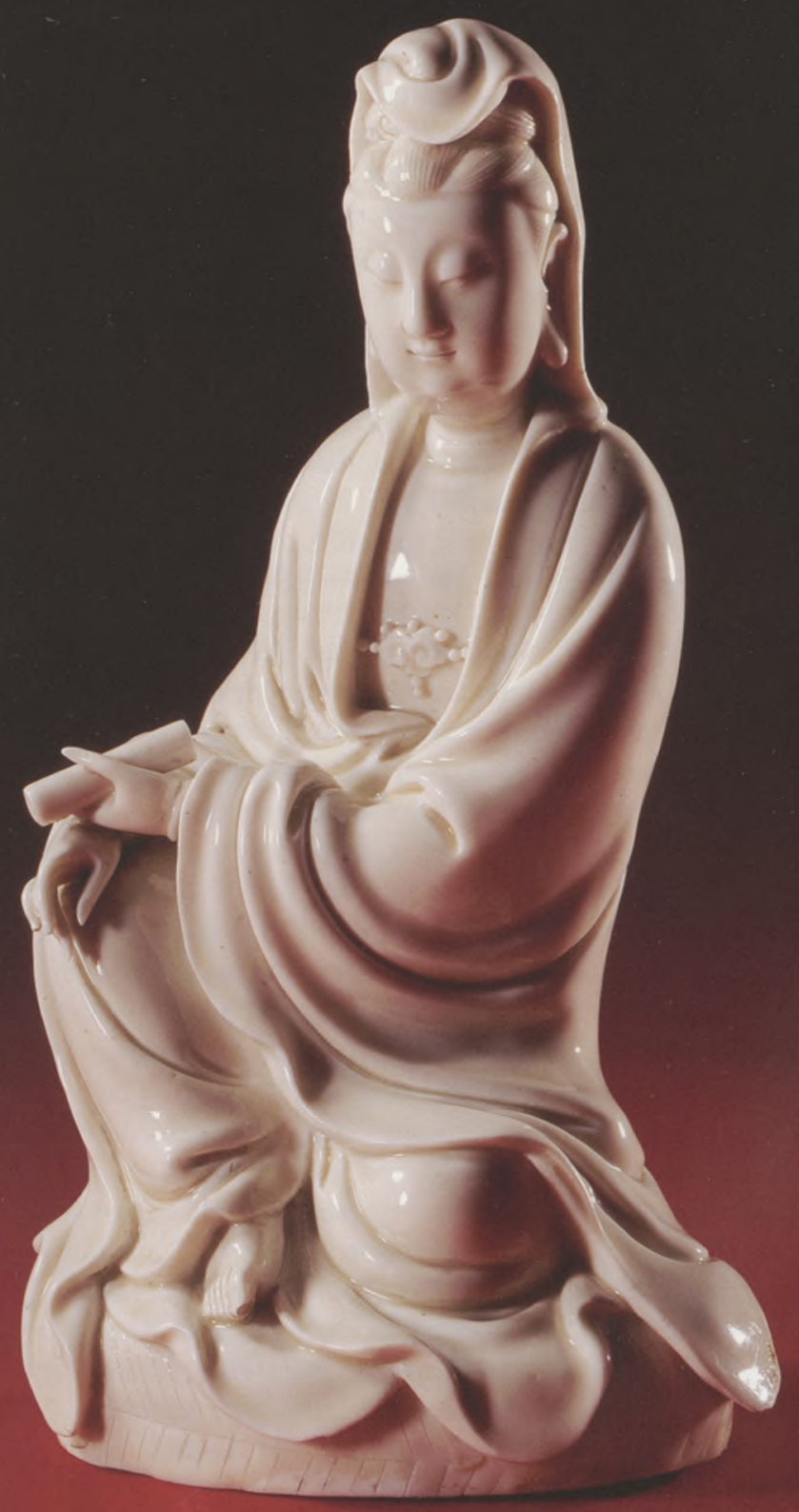


tijd. Deze naar onderwerp zeer wijdlopige lijst bevatte slechts 30 namen, een indicatie voor het belang dat men blijkbaar hechtte aan He's werk.

Tot voor kort werd er van uit gegaan dat de productie van blanc de Chinebeelden de gehele zeventiende eeuw en een groot deel van de achttiende

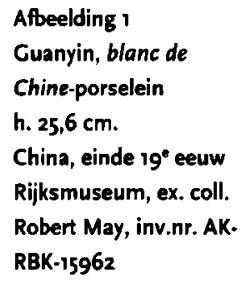
eeuw voortging zonder noemenswaardige ontwikkeling van de stijl. Nu wordt gesteld dat de bloei van de regio als geheel met het einde van de Ming-tijd zozeer ineenstortte dat het onwaarschijnlijk is dat er nog langer opdrachten voor verfijnde, kostbare beelden verstrekt werden. Wel vervaardigden de ovens eenvoudige beeldjes voor de export en natuurlijk gingen zij door met de productie van gewone gebruikskeramiek, iets waar onder alle omstandigheden vraag naar blijft bestaan.

Bij de keuze voor een nieuwe classificatie van het materiaal gaat John Ayers in zijn Blanc de Chine; Divine Images in Porcelain het verste. In Chinese bronnen over vervaardigers van blanc de Chine-beelden van hoogwaardige kwaliteit worden alleen namen genoemd van modelleurs uit de Ming-tijd èn uit de tweede helft van de $19^{e}$ eeuw en later. Alle beelden in zijn catalogus heeft hij dan ook navenant gedateerd: eerste helft $17^{e}$ eeuw òf $19^{e}$ eeuw. Het is even wennen.

\section{De Guanyin van Henri Borel}

Al vóór Donnelly was blanc de Chine een geliefd verzamelonderwerp onder liefhebbers van Chinees porselein en Chinese kunst. Henri Borel (1869-1933) was aan het einde van de $19^{\mathrm{e}}$ en het begin van de $20^{\mathrm{e}}$-eeuw een van de grootste Nederlandse kenners van Chinese kunst en een groot bewonderaar van blanc de Chine-porselein. Borel was sinoloog, had twee jaar van zijn opleiding nabij Amoy genoten (1892-1894) en werkte enige jaren als tolkvertaler voor de overheid in Nederlands-Indië. Borel wilde taalgeleerde, dichter-kunstenaar en wijsgeer in één persoon zijn, volgens hem een voorwaarde om de kunst en cultuur op waarde te schatten. Met de starre westerse aanbidding van het intellect alleen kwam men er niet, zo meende hij, geleerdheid was slechts een hulpmiddel om schoonheid te begrijpen: “...is de intuïtie niet dichter (ja vlak!) bij het hart der dingen dan het onzalige intellect". ${ }^{3}$ In zijn publicaties noemt hij verschillende keren zijn eigen Guanyin-beeld dat het topstuk uit de collectie moet zijn geweest. ${ }^{4}$ Borel kocht het beeld tijdens zijn verblijf in Amoy van een oude sjacheraar met een grof grijnzend gezicht in een onaanzienlijk winkeltje in een smalle, donkere straat van de armoedige en vuile stad. ${ }^{5}$ Groter contrast met het zuiver witte en volkomen harmonische beeld is niet mogelijk. Opmerkelijk is dat Borel in geen van zijn publicaties een woord wijdt aan de ouderdom van het beeld, dat is voor hem van geen belang. Het gaat hem om de directe indruk die het beeld op de opmerkzame toeschouwer maakt. Met zijn zeer gemakkelijke pen weet Borel dat mooi op papier te zetten: '(...) doet eens even de gedachte van u weg, dat het beeld "zo vreemd" is, en zulke grote oren heeft, en zulke "rare" oogen, maar denk eens om de rust, de kalmte, de uit-gestreden, uit-geleden Wijsheid, die een boeddha heeft bereikt, en waarin zijn ziel zich bewust wordt, en kijk dán eens heel ernstig en stil, niet alleen met uwe oogen, maar vooral met den ganschen aandacht van uw ziel naar beelden als nr. 10 [het beeld op afbeelding 2] en 11 hier gereproduceerd'. De neiging bestaat om een dergelijke tamelijk geëxalteerde loftuiting als niet ter zake doende ter zijde te schuiven, maar eigenlijk is het niets anders dan een oproep om met veel aandacht naar een object te kijken. En dat kan men nobit genoég đoeri?. 12:54:49pM 


\section{Afbeelding 2}

De Guanyin van Henri

Borel, blanc de Chine.

porselein

h. $32,5 \mathrm{~cm}$.

China eerste helft

17 eeuw

Foto en voormalige

collectie Ritman

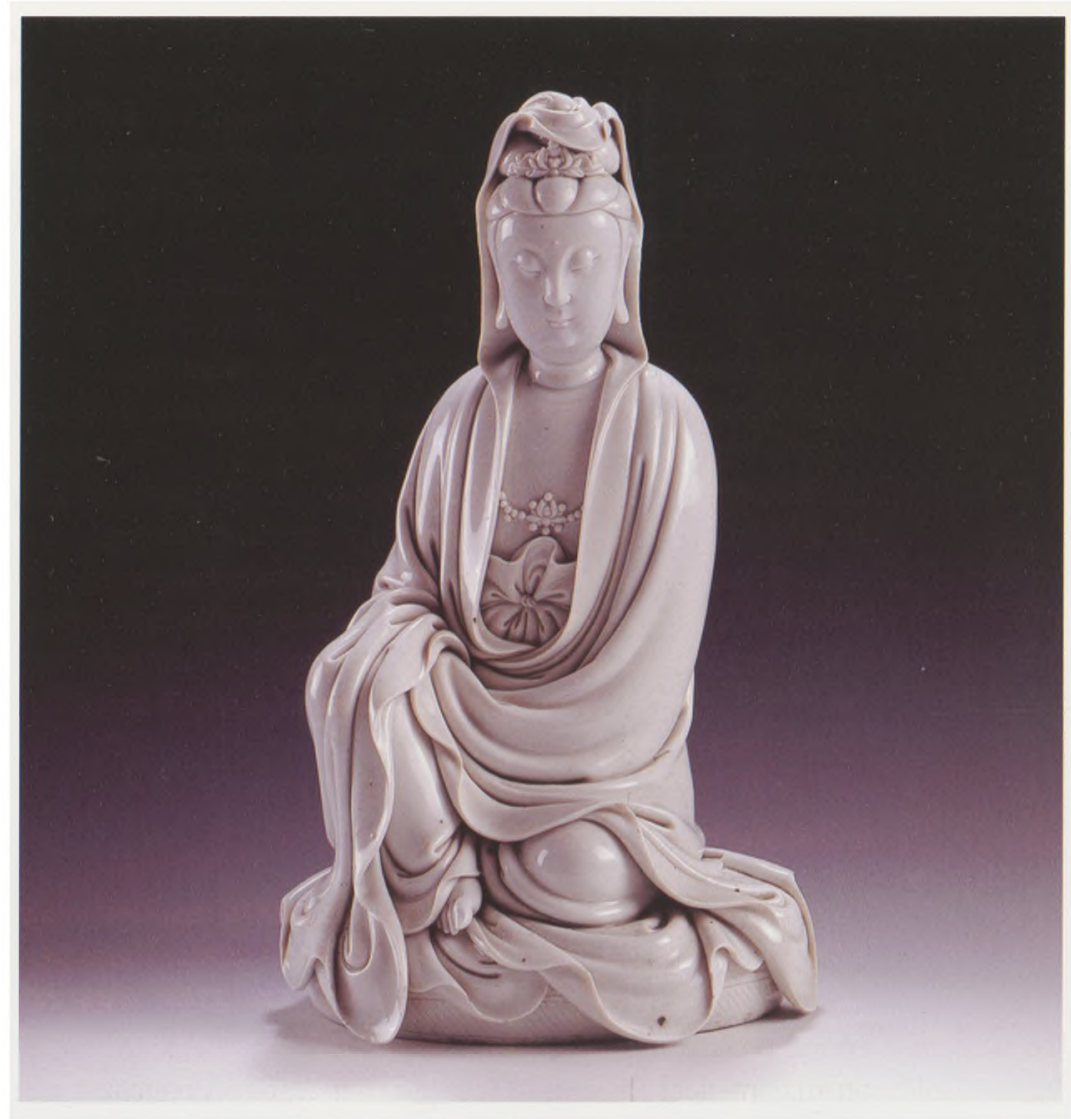

Borels Guanyin is door zijn nazaten verkocht en bevindt zich helaas niet in een openbare verzameling. Een goede foto stelt ons echter toch in de gelegenheid vast te stellen dat Borel inderdaad goed kon kijken: het beeld is zonder meer een prachtig exemplaar.

\section{De Guanyin van Robert May}

Afbeeldingen van de Guanyin van Borel zijn mij nog maar sinds kort bekend. Het gerucht bestond dat een van de Rijksmuseum Guanyins er grote gelijkenis mee vertoonde. Dat blijkt wel mee te vallen, er is eerder sprake van een boeiend verschil. Het beeld dat wat betreft de houding het dichtst in de buurt komt, stamt uit de collectie van Robert May (1873-1962) (afb. 1). Het is een door zijn grote elegantie zeer aantrekkelijk beeld, minder afstandelijk dan sommige andere beelden, zoals bijvoorbeeld het stuk van Borel. Guanyin zit met het rechterbeen opgetrokken en het linker been onder zich. De rechterhand rust op de knie en de linker, met een boekrol in de hand, ligt daar bovenop. Het hoofd is enigszins naar beneden gericht; een doek bedekt het haar en laat slechts een klein deel van het haarsieraad zichbaar. Wanneer Guanyin van Robert May vergeleken wordt met Borels beeld, valt in de eerste plaats op dat de plooien van het gewaad minder fijn en minder gearticuleerd zijn. Hetzelfde geldt voor andere details in het gezicht en in het sieraad op de borst. Het accent komt daardoor vanzelf sterker te liggen op de vloeiende

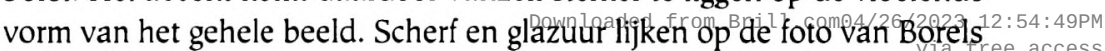


beeld volledig in elkaar te vervloeien, een kenmerk van blanc de Chineporselein van hoge kwaliteit. Bij Mays exemplaar zijn sommige plooien gedeeltelijk dichtgelopen met een eigenlijk te dik glazuur met een geliggroenige tint.

De toegankelijke elegantie, de minder duidelijke articulatie van plooien en details en de plaatselijke ophopingen van glazuur zijn alle drie kenmerken die bij een aantal beelden zijn terug te vinden die Ayers met goede argumenten groepeert rond enkele dateerbare stukken uit het einde van de $19^{e}$ en het begin van de $20^{e}$ eeuw. Dat is een goede reden om de datering van dit beeld bij te stellen. Henri Borel zou dit niet als een bezwaar zien. Het zijn volgens hem alleen 'volslagen onkunstzinnige O.W.-ers' en snobs die groot belang hechten aan de vermeende ouderdom van hun stukken en hechten aan 'een soort Chineesche-kunst-jargon' van de kunsthandel waarmee die ouderdom wordt aangeduid. De ware liefhebber - aldus Borel - maakt door goed te kijken alleen een onderscheid in kwaliteit. ${ }^{6}$

Borels aanstekelijke maar eigenzinnige benaderingswijze wordt tegenwoordig gecomplementeerd met gedegen onderzoek. Het zijn de visies van Borel en Ayers samen die het mogelijk maken opnieuw naar de beelden van blanc de Chine-porselein in het Rijksmuseum te kijken en tot een nieuwe waardering, classificatie en datering te komen.

In de toekomst zullen archeologisch en historisch onderzoek in China waarschijnlijk meer kennis van dit porselein opleveren. Alle drie de recente publicaties benadrukken dat de samenwerking tussen deskundigen in China en het Westen nog in de kinderschoenen staat. Het is te hopen dat intuïtie en onzalig intellect elkaar zullen blijven versterken. Wellicht zijn er al over een aantal jaren goede redenen om de datering van Robert Mays Guanyin opnieuw te herzien, maar dat mag op onze waardering voor het beeld niet van invloed zijn, zoveel hebben we wel geleerd van Henri Borel.

\section{Noten}

* Met dank aan Pier Terwen voor zijn informatie over Borel.

1. J. Ayers with an essay by Yuan Bingling, Blanc de Chine; divine images in porcelain (tent.cat. China Institute Gallery, New York), New York, 2002; R. Kerr, J. Ayers e.a., Blanc de Chine; porcelain from Dehua, Richmond, 2002; R.H. Rosenblum, Blanc de Chine; the great porcelain of Dehua, Berkeley/Toronto, 2002.

2. Ayers, Op.cit., p. 28.

3. H. Borel, Het Schoone eiland, een tweede boek van wijsheid en schoonheid uit China, Amsterdam, z.j. [1922], tweede druk, p. 138.

4. H. Borel, Kwan Yin; een boek van goden en de hel, Amsterdam, z.j. [1919], tweede druk, pp. 62-68 (met afbeelding); Chineesche Kunst; gedenkboek van de tentoonstelling gehouden te Batavia in December 1903 door den "NederlandschIndischen Kunstkring" te Batavia, Amsterdam, z.j. [1904], pp. 9 en 15 (met afbeelding én op omslag); Chineesche Kunst, Amsterdam, 1906 (zelfde tekst als gedenkboek, eveneens met afbeelding én op omslag).

5. Borel, Kwan Yin, p. 66-67.

6. Borel, 'Oude en nieuwe Chineesche kunst', Het Schoone eiland, pp. 89-97. 